\title{
Restoration of motor function following spinal cord injury via optimal control of intraspinal microstimulation: toward a next generation closed-loop neural prosthesis
}

\author{
Peter J. Grahn ${ }^{1}$, Grant W. Mallory ${ }^{2}$, B. Michael Berry ${ }^{1}$, Jan T. Hachmann ${ }^{2}$, Darlene A. Lobel ${ }^{3}$ and \\ J. Luis Lujan ${ }^{2,4} *$
}

${ }^{1}$ Mayo Clinic College of Medicine, Mayo Clinic, Rochester, MN, USA

${ }^{2}$ Department of Neurologic Surgery, Mayo Clinic, Rochester, MN, USA

${ }^{3}$ Department of Neurosurgery, Cleveland Clinic, Cleveland, $\mathrm{OH}$, USA

${ }^{4}$ Department of Physiology and Biomedical Engineering, Mayo Clinic, Rochester, MN, USA

\section{Edited by:}

Mitsuhiro Hayashibe, University of

Montpellier, France

\section{Reviewed by:}

Ken Yoshida, Indiana

University-Purdue University

Indianapolis, USA

Lee Fisher, Univeristy of Pittsburgh, USA

\section{*Correspondence:}

J. Luis Lujan, Departments of Neurologic Surgery and Physiology and Biomedical Engineering, Mayo Clinic, 200 First Street SW,

Rochester, MN 55905, USA

e-mail: luis.lujan@mayo.edu
Movement is planned and coordinated by the brain and carried out by contracting muscles acting on specific joints. Motor commands initiated in the brain travel through descending pathways in the spinal cord to effector motor neurons before reaching target muscles. Damage to these pathways by spinal cord injury $(\mathrm{SCl})$ can result in paralysis below the injury level. However, the planning and coordination centers of the brain, as well as peripheral nerves and the muscles that they act upon, remain functional. Neuroprosthetic devices can restore motor function following $\mathrm{SCl}$ by direct electrical stimulation of the neuromuscular system. Unfortunately, conventional neuroprosthetic techniques are limited by a myriad of factors that include, but are not limited to, a lack of characterization of non-linear input/output system dynamics, mechanical coupling, limited number of degrees of freedom, high power consumption, large device size, and rapid onset of muscle fatigue. Wireless multi-channel closed-loop neuroprostheses that integrate command signals from the brain with sensor-based feedback from the environment and the system's state offer the possibility of increasing device performance, ultimately improving quality of life for people with $\mathrm{SCl}$. In this manuscript, we review neuroprosthetic technology for improving functional restoration following $\mathrm{SCl}$ and describe brain-machine interfaces suitable for control of neuroprosthetic systems with multiple degrees of freedom. Additionally, we discuss novel stimulation paradigms that can improve synergy with higher planning centers and improve fatigue-resistant activation of paralyzed muscles. In the near future, integration of these technologies will provide SCl survivors with versatile closed-loop neuroprosthetic systems for restoring function to paralyzed muscles.

Keywords: spinal cord injury, brain machine interface, closed-loop control, feedback control, neuroprosthetics, sensors, implantable systems

\section{INTRODUCTION}

Approximately 300,000 individuals in the United States, and more than 2.5 million individuals worldwide, are affected by traumatic spinal cord injury (SCI) (National Spinal Cord Injury Statistical Center, 2013). Overall health-care related cumulative costs are estimated to exceed $\$ 9$ billion annually in the United States alone (DeVivo, 2012). In 2010, 36.5\% of SCI resulted from motor vehicle accidents, $28.5 \%$ from falls, $14 \%$ from violence (including gunshot wounds), $9 \%$ from sports accidents, and $11 \%$ from other incidences not reported in detail (National Spinal Cord Injury Statistical Center, 2013). The demographic profile has changed over the last 40 years to involve older aged individuals. However, males still comprise the majority of injuries (Sekhon and Fehlings, 2001; DeVivo, 2012; Lenehan et al., 2012; National Spinal Cord Injury Statistical Center, 2013).

Traumatic SCI can occur when an excessive load to the spinal column is transmitted (directly or indirectly) to the spinal cord
(Rowland, 1991; Watson et al., 2009). Damage to the spinal cord begins at the moment of injury, when displaced fragments of bone, disc material, or ligaments typically cause bruises or tears to spinal cord tissue (McDonald and Sadowsky, 2002). However, paralysis has been observed with no radiographic evidence of damage to the spinal cord or vertebral column (Pang and Wilberger, 1982; Mirovsky et al., 2005; Mahajan et al., 2013). Regardless of the injury mechanism, SCI involves permanent sensorimotor and autonomic deficits (Scivoletto et al., 2014), with long term complications including muscle atrophy and increased risk of cardiovascular disease (Phillips et al., 1998; Chen et al., 1999).

Most spinal cord injuries do not completely sever the spinal cord (Marino et al., 2003; National Institute of Neurological Disorders and Stroke, 2013). Instead, key pathways necessary for signal transmission between the brain and the rest of the body are disrupted. Spinal cord injuries can be classified as complete 
and incomplete injuries (Marino et al., 2003). Complete injuries are indicated by a total lack of sensory and motor function below the level of injury. In contrast, the ability to convey messages to or from the brain is not completely lost in cases of incomplete injury. That is, limited sensation and movement remain below the level of injury. Although SCI interrupts connections between the brain and effector muscles, key planning, coordination, and effector centers above and below the injury remain intact (Krajl et al., 1986; Triolo et al., 1996; Jilge et al., 2004; Minassian et al., 2004; Fisher et al., 2008, 2009; Yanagisawa et al., 2011; Wang et al., 2013; Collinger et al., 2014). Functional electrical stimulation (FES) is a form of therapy that applies external currents into intact neuromuscular circuitry below the level of injury, activating intact neural components to cause muscle contractions that can lead to restoration of motor function (Jackson and Zimmermann, 2012).

This manuscript reviews current therapeutic applications of electrical stimulation of the spine for providing functional coordination of muscle contraction and restoring function to paralyzed muscles. Additionally, this manuscript describes the development of neurostimulation technologies and control strategies, combining brain signals, optimal control algorithms, and emerging FES strategies to develop a clinically-translatable FES system that optimizes restoration of neurologic function following SCI (Figure 1).

\section{ELECTRICAL STIMULATION OF EXCITABLE TISSUE}

The use of electrical stimulation for investigating the function of the nervous system began with the Italian physician and scientist Luigi Galvani (Galvani and Aldini, 1792). Galvani discovered that nerves and muscles are electrically excitable, and was able to evoke muscle contractions in frog legs by stimulating them with brief jolts of electricity, produced by static generators (Hambrecht, 1992). Since then, it has been well established that nerve cells

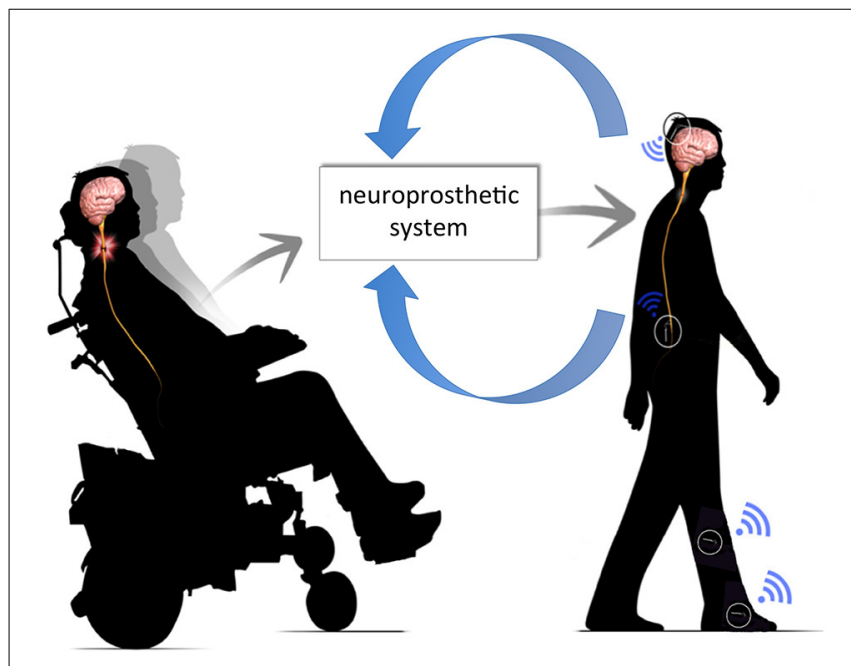

FIGURE 1 | Neuroprosthetic system. The neuroprosthetic system is capable of interpreting volitional movement signals from the brain, integrating these commands with sensor feedback (e.g., joint angle, limb velocity, etc.) and, delivering appropriate commands into intact neural circuitry below the level of injury. can be activated using electrical currents delivered into neural tissue via stimulating electrodes (Glenn et al., 1976; Branner et al., 2001; Brill et al., 2009; Kilgore et al., 2009; Kent and Grill, 2013; Nishimura et al., 2013). Active nerve cells fire electrical impulses, also known as action potentials, that travel along the nerve axon and propagate across neuromuscular junctions via neurotransmitter signaling (Bean, 2007; Meriney and Dittrich, 2013). In turn, this signaling mechanism causes muscle fibers connected to nerve fibers (i.e., motor unit) to contract (Hughes et al., 2006).

\section{ELECTRICALLY EVOKED MUSCLE ACTIVATION}

The strength of stimulation-evoked muscle contractions can be controlled by varying the frequency, amplitude, and pulsewidth of the external stimuli (Grobelnik, 1973; Kralj et al., 1988; Kralj and Bajd, 1989; Bhadra and Peckham, 1997). At low frequencies, individual muscle twitches are evoked with each stimulus pulse. At higher frequencies, responses to individual stimuli fuse and muscles respond with smooth contractions. Higher stimulus frequencies produce stronger muscle contractions, but also increase the rate of muscle fatigue (Tanae et al., 1973; McDonnall et al., 2004; Bamford, 2005). Activation of motor units can be achieved using different stimulation modalities: transcutaneous stimulation, percutaneous stimulation, intramuscular stimulation, peripheral nerve stimulation, and spinal stimulation.

\section{TRANSCUTANEOUS STIMULATION}

Transcutaneous stimulation, also known as surface stimulation, relies on stimulating electrodes placed on the skin surface directly over the muscle motor points (i.e., locations that produce an optimal balance between contraction strength and stimulation amplitude) (Hirokawa et al., 1990; Scremin et al., 1999; Mangold et al., 2005). This non-invasive, reversible, and inexpensive technique has been successfully used in locomotion and hand grasp systems (Kralj and Bajd, 1989; Popovic et al., 2005). However, transcutaneous muscle stimulation has multiple practical limitations. Specifically, the skin offers a high resistance compared to muscle tissue (Bîrlea et al., 2014). For this reason, higher stimulation currents $(>30 \mathrm{~mA})$ are required to achieve desired motor responses using surface stimulation (Triolo et al., 2001; Lujan and Crago, 2009). Additionally, the limited degree of selectivity can lead to activation of antagonist muscle groups or an inability to selectively activate deep muscle groups (Schmit and Mortimer, 1997; Triolo et al., 2001). Furthermore, current spread due to suboptimal electrode placement and limited stimulation specificity can result in pain (Niddam et al., 2001).

\section{PERCUTANEOUS STIMULATION}

Percutaneous stimulation systems rely on intramuscular needle electrodes that pass through the skin and stimulate target muscles (Caldwell and Reswick, 1975; Stanic et al., 1978; Malezic et al., 1984; Marsolais and Kobetic, 1986; Bogataj et al., 1989). This allows activation of deep muscles and provides isolated, selective, and repeatable muscle contractions. Percutaneous stimulation requires lower stimulation intensities compared to transcutaneous stimulation. However, increased risks of infection, lead breakage, and movement restrictions limit the use of 
percutaneous stimulation outside of a laboratory environment (Knutson et al., 2002).

\section{IMPLANTED INTRAMUSCULAR AND PERIPHERAL NERVE STIMULATION}

Implanted neurostimulation systems are associated with electrical current delivery via both intramuscular and nerve cuff electrodes (Rabischong and Ohanna, 1992; Peckham et al., 2002; Guiraud et al., 2006). As the name implies, intramuscular stimulation relies on electrodes implanted directly into the muscle (Crago et al., 1980; Hobby et al., 2001; Peckham et al., 2001, 2002; Peckham and Knutson, 2005; Kilgore et al., 2008). Peripheral nerve stimulation relies on electrode cuffs that are surgically placed around nerves innervating target muscles (Stein et al., 1975; Hoffer et al., 1996; Strange and Hoffer, 1999; Sinkjaer, 2000; Branner et al., 2001; Brill et al., 2009; Fisher et al., 2009; Polasek et al., 2009). Although capable of evoking strong, selective, and repeatable muscle activation, intramuscular and nerve cuff stimulation techniques often recruit the largest and most fatigable motor units first, resulting in early fatigue onset (Popovic et al., 2002). Discontinuous activation of muscle compartments and interleaved frequency stimulation have both been reported to delay fatigue onset (Boom et al., 1993; McDonnall et al., 2004). Saigal et al. demonstrated fatigue-resistant stepping in a spinalized cat by stimulating the lumbrosacral cord via interleaved stimulation (Saigal et al., 2004). Interleaved stimulation reduces muscle fatigue by decreasing the stimulation frequency (Mushahwar and Horch, 1997; Tai et al., 2000). The asynchronous nature of interleaved stimulation is designed to evoke fused contractions despite a lack of tetanic firing in individual motor units. However, the limited number of controllable degrees of freedom, high power consumption, and other technological and practical limitations have restricted the widespread application of electrical stimulation therapy outside research environments (Peckham and Knutson, 2005; Ragnarsson, 2008; Creasey and Craggs, 2012).

\section{SPINAL CORD STIMULATION}

Direct stimulation of the spinal cord may be advantageous over conventional FES techniques as spinal stimulation provides an opportunity to directly activate higher level circuitry, which oversees and coordinates motor function (Minassian et al., 2004, 2007; Bamford, 2005; Gerasimenko et al., 2008; Bamford and Mushahwar, 2011; Holinski et al., 2011; van den Brand et al., 2012; Angeli et al., 2014). Two modalities of spinal stimulation have been described: epidural and intraspinal stimulation.

In epidural stimulation, stimulating electrodes are placed directly over the spinal cord (Lavrov et al., 2008; Hachmann et al., 2013). Two recent studies reported that neuromodulation of spinal circuitry via epidural stimulation, combined with intense physical rehabilitation, was capable of allowing individuals with incomplete and complete SCI to process conceptual, auditory and visual feedback to regain voluntary control of paralyzed muscles for short durations of time. Results of these studies suggest some degree of residual connectivity through the area of SCI (Harkema et al., 2011; Angeli et al., 2014). These studies, although promising, require using rigorous patient selection and replication in larger patient populations.
In intraspinal microstimulation (ISMS), stimulating electrodes are implanted within the ventral gray matter of the spinal cord (Bamford and Mushahwar, 2011). ISMS is hypothesized to directly activate alpha motor neurons, preferentially activating fatigue resistant muscle fibers (Gorman, 2000; Bamford, 2005). Several studies have highlighted the potential of ISMS to restore bladder and respiratory function, as well as upper and lower extremity function in animal models (Mushahwar and Horch, 2000a,b; Mushahwar et al., 2002; Moritz et al., 2007; Bamford et al., 2010; Bamford and Mushahwar, 2011; Nishimura et al., 2013; Sunshine et al., 2013).

\section{INTRASPINAL MICROSTIMULATION (ISMS)}

Intraspinal stimulation has been extensively used to study the effects of electrical stimulation on the central nervous system, as well as synaptic delays and network interconnections across spinal pathways (Renshaw, 1946; Jankowska and Roberts, 1972a,b; Gustafsson and Jankowska, 1976). More recently, ISMS has been used to investigate the organization of motor circuitry within the spinal cord in amphibious, rodent, and feline animal models (Bizzi et al., 1991; Giszter et al., 1993; Tresch and Bizzi, 1999; Lemay et al., 2001, 2009; Saltiel et al., 2001; Lemay and Grill, 2004).

Similarly, over the past 15 years, ISMS has been used to investigate restoration of motor function in spinalized and anesthetized rodents and cats (Mushahwar et al., 2002; Bamford, 2005; Pikov et al., 2007; Yakovenko et al., 2007; Holinski et al., 2011; Kasten et al., 2013; Sunshine et al., 2013). Work performed by Lau et al. demonstrated that ISMS is capable of producing standing in cats for over $20 \mathrm{~min}$ (Lau et al., 2007). The lower stimulation amplitudes associated with intraspinal stimulation (in the order of a few microamperes) are believed to be, at least in part, responsible for the longer periods of muscle contraction observed (Bamford, 2005). Other studies suggest that the fatigue resistance observed with ISMS techniques is the result of preferential activation of type I slow-twitch fatigue-resistant motor fibers (Mushahwar, 2000; Mushahwar and Horch, 2000a; Saigal et al., 2004; Bamford, 2005; Nishimura et al., 2013). Moreover, Bamford et al. showed ISMS recruitment of up to $44 \%$ fatigue-resistant muscle fibers compared to less than $1 \%$ fatigue-resistant muscle fibers recruited using peripheral nerve cuff stimulation (Caldwell and Reswick, 1975; Marsolais and Kobetic, 1986; Bamford, 2005). As such, when combined with interleaved stimulation, ISMS has been associated with further decrease in muscle fatigue (Rack and Westbury, 1969; McDonnall et al., 2004; Lau et al., 2007; Mushahwar et al., 2007).

The close proximity of spinal motor centers to higher control centers responsible for controlling motor function, together with the improved fatigue response, make ISMS an excellent alternative for restoring locomotor function in individuals with SCI (Etlin et al., 2014; Guertin, 2014). However, before spinal or other electrical stimulation technology can be clinically used to optimally improve quality of life for individuals with SCI, appropriate stimulation control paradigms must be established. 


\section{OPTIMAL CONTROL PARADIGMS}

Electrical stimulation systems have been previously used to assist respiratory function (Kaneyuki et al., 1977; Gorman, 2000; Posluszny et al., 2014), hand grasp (Avestruz et al., 2008; Skarpaas and Morrell, 2009; Rosin et al., 2011; Gan et al., 2012; Basu et al., 2013; Grant and Lowery, 2013), locomotion (Behrend et al., 2009), as well as bladder and bowel function (Lee et al., 2004; Shon et al., 2010a,b; MacDonald et al., 2013) in patients with SCI. These FES systems have relied on a variety of control strategies, ranging from linear models to adaptive controllers, but all aimed at enhancing stimulation-evoked functional responses. Many neuroprosthetic control systems rely on feedforward configurations (Moro et al., 1999; Molinuevo et al., 2000), in which controller output depends only on user inputs (e.g., stimulus parameters). These controllers have fast response times, but do not make corrections if the target and actual outputs differ (Lee et al., 2009). Furthermore, these controllers will not alter their response in the face of unexpected internal or external perturbations (Blaha and Phillips, 1996; Lee et al., 2006). However, the highly non-linear nature of muscle responses, coupled with environmental perturbations found in activities of daily living, require that optimal neuroprosthetic control paradigms rely on feedback signals. Feedback-based control systems continuously monitor musculoskeletal system outputs and adjust stimulation parameters if the stimulation-evoked musculoskeletal system outputs (e.g., limb position, force) differ from the desired outputs (Lujan and Crago, 2009; Griessenauer et al., 2010; Chang et al., 2012). This guarantees the system can respond to and compensate for unforeseen perturbations. Feedback control has been previously used for control of hand grasp (Lujan and Crago, 2009), standing posture (Fraix et al., 2006; Rosin et al., 2011), and locomotion (Roham et al., 2007; Takmakov et al., 2010; Fitzgerald, 2014) in SCI individuals. Simple feedback control can be improved by using adaptive systems (Karniel and Inbar, 2000; Kobravi and Erfanian, 2012). Adaptive algorithms modify controller behavior in response to changes in the system and the environment (Chizek et al., 1988; Narendra, 1990; Narendra and Parthasarathy, 1990; Teixeira et al., 1991; Kostov et al., 1995; Davoodi and Andrews, 1998, 1999; Jonić et al., 1999; Abbas and Riener, 2001).

Studies have demonstrated the ability of neural networks to successfully control motor neuroprostheses, both in paraplegic (Riess and Abbas, 1999, 2000, 2001; Nataraj et al., 2013) and tetraplegic individuals (Fujita et al., 1998; Lujan and Crago, 2009). Artificial neural networks (ANNs) can model static and dynamic non-linear systems (Durfee, 1989; Funahashi, 1989; Hornik et al., 1989; Chakraborty et al., 1992; Barron, 1993; Lan et al., 1994; Piche, 1994; Graupe and Kordylewski, 1995; Hassoun, 1995; Kostov et al., 1995; Chang et al., 1996; Chen et al., 1997; Demuth and Beale, 2000). Additionally, ANNs can generalize from experimental input/output data, eliminating the need for analytical models of the system (Funahashi, 1989; Hornik et al., 1989; Graupe and Kordylewski, 1995; Hassoun, 1995; Narendra, 1996; Demuth and Beale, 2000). Furthermore, ANNs are less sensitive to noise and easily implemented in hardware (Narendra, 1996). Moreover, ANN-based controllers allow changes to the controller without requiring changes in data collection or controller training methods. Backpropagation neural networks have been used to model the non-linear relationship between stimulus intensity and stimulation-evoked responses (Fujita et al., 1998; Lujan and Crago, 2009). Additionally, ANNs have been successfully used to create inverse dynamic models of musculoskeletal systems for neuroprosthetic control (Chang et al., 1997; Yoshida et al., 2002). These models are particularly useful for learning the characteristics of electrically-activated muscles in coupled multijoint systems acted upon by redundant muscles (Adamczyk and Crago, 1997, 2000; Lujan and Crago, 2009).

Thus, optimal neuroprosthetic control systems should rely on a combination of non-linear feedforward and feedback techniques in order to pre-emptively reduce the amount of error in real-time while minimizing time delays inherent to feedback control systems. Development of such optimal closedloop neuroprosthetic controllers will require high-quality sensors that can withstand daily use under a wide range of daily life activities.

\section{FEEDBACK SIGNALS FOR OPTIMAL CONTROL OF NEURAL PROSTHESES}

Neuroprosthetic systems with feedback control are capable of identifying, decoding, and extracting features from appropriate input signals in order to respond to unforeseen perturbations and changes in the environment (Bhadra et al., 2002; Dominici et al., 2012; Holinski et al., 2013). However, optimal feedback modulation for clinical application will require fully implantable smart sensors that provide consistent and reliable chronic information to the control system (Shih et al., 2012; Peckham and Kilgore, 2013). There is already a wide range of sensors that can detect and measure information about the system and its environment. The most commonly used sensors include electrophysiological sensors, chemical sensors, force transducers, and magnetic sensors. Electrophysiological sensors measure potential differences generated by muscle (i.e., myoelectric signals) and neural tissue (e.g., electroencephalogram, electrocorticogram, electroneurogram) (Leuthardt et al., 2004; Müller-Putz et al., 2005; Holinski et al., 2013). These sensors can monitor muscle state and evaluate expected muscle responses. In turn, this allows adaptation of stimulation parameters in the presence of muscle fatigue (Hayashibe et al., 2011; Zhang et al., 2013). Chemical sensors (e.g., carbon fiber microelectrodes coupled to fast scan cyclic voltammetry devices) can detect changes in stimulationevoked analytes (e.g., neurotransmitters) (Bledsoe et al., 2009; Chang et al., 2012) that can be used to modulate stimulation levels. Force transducers (e.g., piezoelectric devices, accelerometers) can be used to detect changes in limb position, ground reaction forces, heel strike, and other events that are critical for event detection and optimal control of stimulation (Tan et al., 2004). Magnetic sensors detect changes in magnetic fields and can be used to detect limb position and orientation (Bhadra et al., 2002; Tan et al., 2004). However, having reliable sensors is not enough to develop an optimal feedback controller. In order for the signals measured by these sensors to be of clinical use, they must be properly decoded and integrated with both existing and novel neuroprosthetic control systems (Shadmehr et al., 2010). This will most likely happen in the way of a brain machine interface. 


\section{BRAIN MACHINE INTERFACES}

Brain machine interfaces (BMI) are neural interface systems that can record, analyze, and decode brain signals (Wang et al., 2010) to infer volitional intent, which in turn can be used to control limb movement and assistive devices (Figure 2) (Leuthardt et al., 2004; Hochberg et al., 2006; Schwartz et al., 2006; Miller et al., 2010; Carmena, 2012; Fifer et al., 2012). Brain commands may be recorded using sensors located on the scalp (electroencephalogram), the surface of the brain (electrocorticogram), or the brain parenchyma using intracortical electrodes that record activity from single neurons (single unit recording) or groups of neurons (local field potentials) (Figure 3). Electroencephalographic recordings offer a non-invasive recording technique that is safe and easy to implement. However, controlling multiple degrees of freedom with electroencephalographic signals has proven difficult due to challenges with extracting and classifying individual signal features as well as an inherent low spatial resolution (Yang et al., 2011). Single unit recordings and local field potentials offer excellent signal resolution, but are highly invasive (Buzsáki et al., 2012). Single unit recordings capture the activity of distinct neurons. The high spatial and temporal resolution provided by single unit recordings allows for precise measurements of neuronal spikes (Buzsáki et al., 2012). The downfall to single unit recordings is a difficulty isolating specific neural activity due to crosstalk from neighboring cells (Bai and Wise, 2001). Furthermore, single unit recordings can be biased toward activity from larger neurons adjacent to the intended neuron (Buzsáki et al., 1983). Finally, electrode migration, immune responses (e.g., glial scarring), and disruption of surrounding neural tissue interfere with signal quality and limit reliable single unit activity to acute recording conditions (Carter and Houk, 1993; Polikov et al., 2005). Local field potentials reflect a weighted average of integrative processes and associations between cells that can be detected over longer distances through extracellular space (Logothetis, 2003a,b; Andersen et al., 2004; Bronte-Stewart et al., 2009; Buzsáki et al., 2012; Rosa et al., 2012). Unfortunately, the longer recording range of local field potential techniques is associated with decreased spatial resolution. Electrocorticogram presents a good balance between risks and benefits, as it provides good spatiotemporal resolution without damaging underlying cortical tissue (Leuthardt et al., 2004; Wilson et al., 2006; Schalk et al., 2008; Moran, 2010; Slutzky et al., 2010).

Extracted brain signals must undergo filtering to remove movement artifacts and electrical noise before they can be used by a BMI and neuroprosthetic controller to generate motor commands (Kowalski et al., 2013). Filtered signals must be analyzed using classifiers and signal processing algorithms that identify unique features or signatures (Kowalski et al., 2013). In turn, these features are mapped to specific functions and/or degrees of freedom that control neuroprosthetic systems and assistive devices (Pfurtscheller et al., 2003; Musallam et al., 2004; Müller-Putz et al., 2005; Jackson et al., 2006; Moritz et al., 2008; Daly et al., 2009; Chadwick et al., 2011).

Pioneering work by Georgopoulos et al. used single unit recordings to establish a high degree of correlation between arm movement and cortical activity within a non-human primate (Georgopoulos et al., 1986). Subsequently, several studies in nonhuman primates and SCI-survivors have demonstrated stable, chronic, intracortical recordings using microelectrode arrays such as the Utah and Michigan arrays (Wessberg et al., 2000; Serruya et al., 2002; Taylor et al., 2002; Pfurtscheller et al., 2003; Suner et al., 2005; Cheung, 2007; Cheung et al., 2007; Moritz et al., 2008; Langhals and Kipke, 2009; Sharma et al., 2010, 2011; Do et al., 2011; Hochberg et al., 2012). Cortical signatures can be identified from their spatial, temporal, and frequency-dependent features (Nicolas-Alonso and Gomez-Gil, 2012). However, BMI

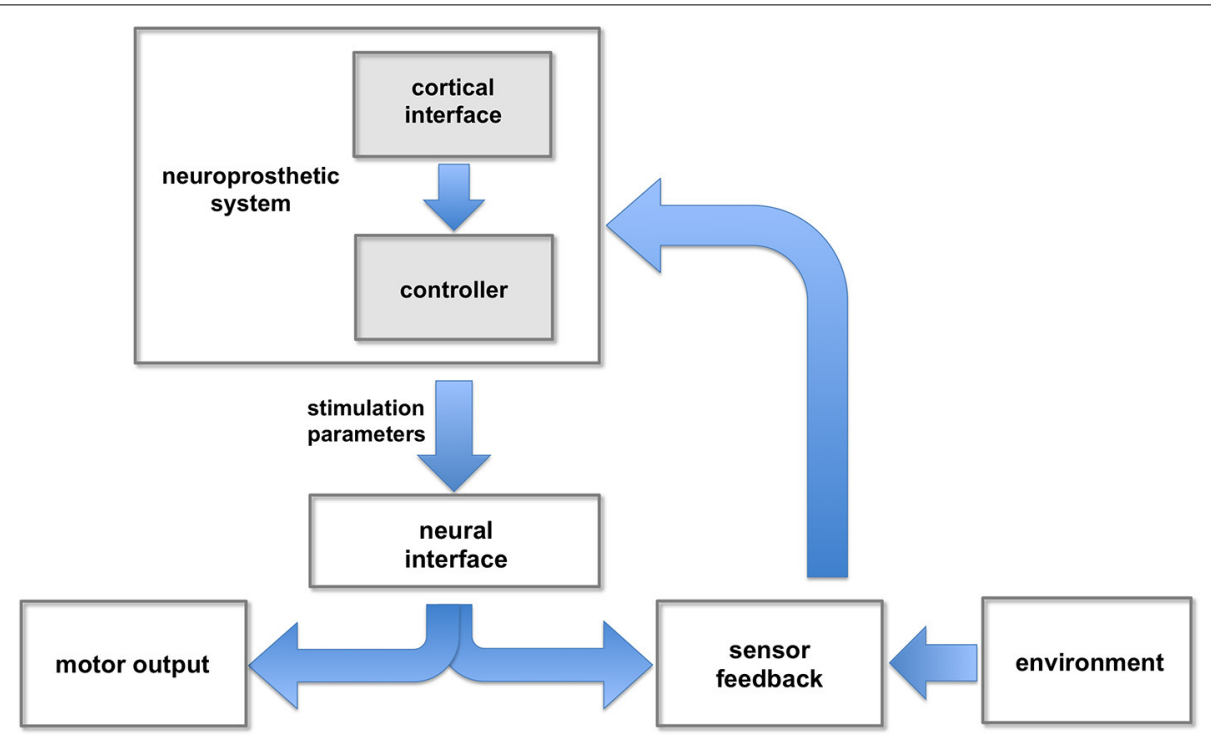

FIGURE 2 | Neuroprosthetic control. The neuroprosthetic controller receives user commands (e.g., intended movement) extracted from cortical signals, and feedback information from different sensors. These inputs are combined and processed to adjust the stimulation parameters responsible for evoking intended movements. 


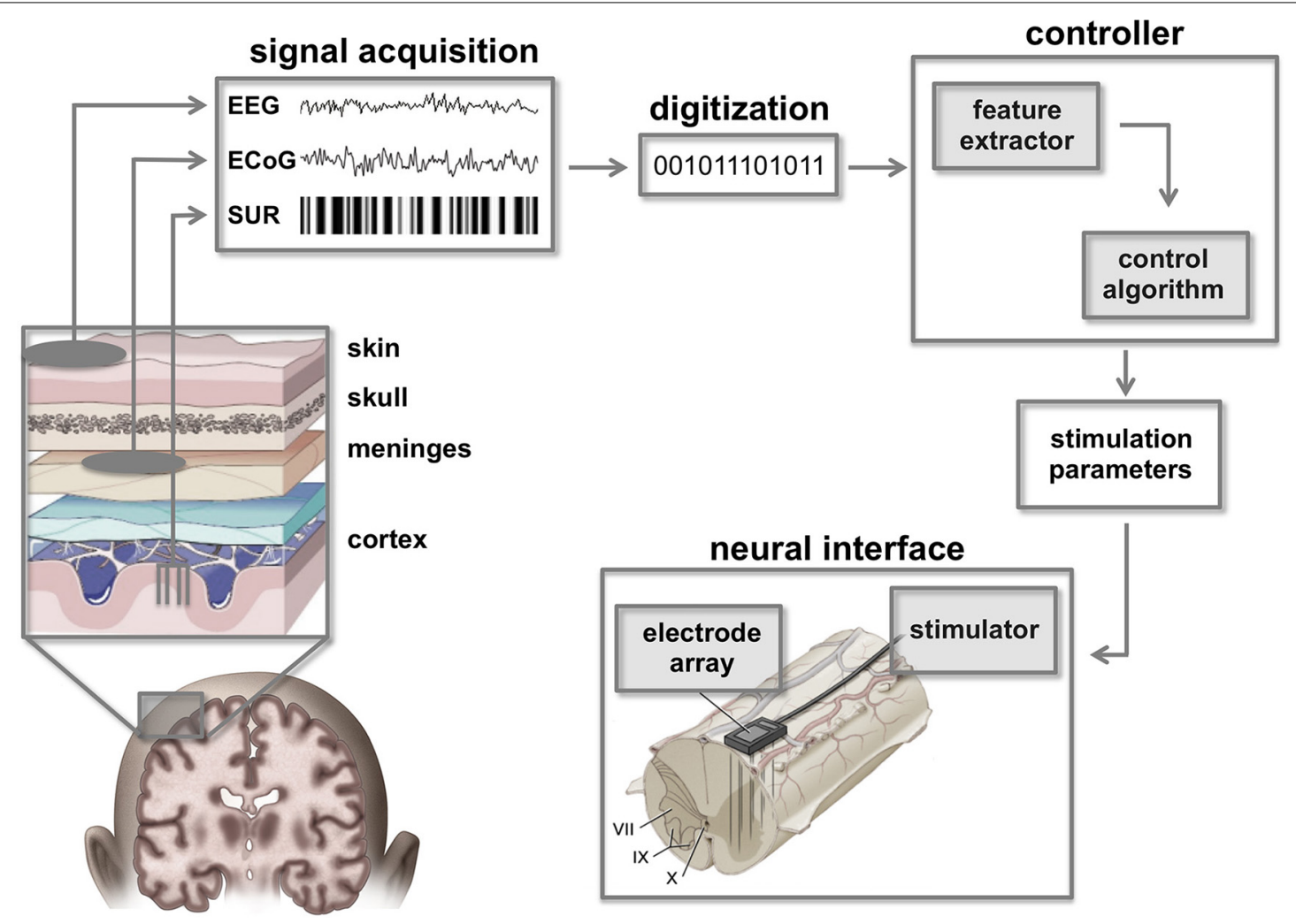

FIGURE 3 | Cortico-spinal neuroprostheses. Command signals from the brain can be extracted using a variety of brain signal recording techniques such as single unit recordings (SUR), electrocorticographic signals (ECoG), or electroencephalographic signals (EEG). Raw signals must be digitized and filtered to extract essential features that can be classified by the controller in order to calculate appropriate stimulation parameters. In turn, these parameters are used by a neural interface to activate spinal circuitry below the level of injury. Figure adapted from Smart Draw LifeART Collection Images and Lobel and Lee (2014). application to complex neuroprosthetic control has been limited due to the difficulty of extracting sufficient numbers of unique signatures for control of systems with multiple degrees of freedom (Shih et al., 2012). Ongoing efforts in decoding algorithms, together with advances in neural training techniques such as motor imagery, have recently improved feature extraction, allowing SCI survivors to control complex movements using BMI (Wang et al., 2009, 2013; Chao et al., 2010; Yanagisawa et al., 2011).

\section{CONCLUSIONS}

Recent advances in the fields of BMIs and electrical stimulation therapy provide a promising outlook for patients with SCI. However, it is clear that successful restoration of independence for SCI survivors requires integration of selective electrical stimulation techniques, feedback control, and optimal control algorithms. As is the case in normal human neurophysiology, selective muscle activation as well as integration of force feedback, balance, proprioception, and reduction of muscle fatigue are all critical for motor function. Therefore, next-generation closed-loop neuroprosthetic systems must integrate fully implantable multichannel stimulators and feedback sensors with adaptive control systems. Furthermore, control algorithms must be designed for seamless integration with BMI systems and real-time processing, integration, and transmission of feedback control signals. Devices that are capable of coupling such novel stimulation, intention detection, proprioceptive sensing, and control algorithms are currently under development, with clinical translation just beyond the horizon. Ultimately, these technologies will provide SCI survivors with increased independence in daily life, improved overall health, and enhanced quality of life.

\section{ACKNOWLEDGMENTS}

This work was supported by NIH R21 NS087320, The Grainger Foundation, and a gift from Louise Chapman.

\section{REFERENCES}

Abbas, J. J., and Riener, R. (2001). Using mathematical models and advanced control systems techniques to enhance neuroprosthesis function. Neuromodulation 4, 187-195. doi: 10.1046/j.1525-1403.2001.00187.x

Adamczyk, M. M., and Crago, P. E. (1997). "Integrated hand/wrist control in a neuroprosthesis for individuals with tetraplegia," in 19th International Conference of IEEE EMBS (Chicago, IL).

Adamczyk, M. M., and Crago, P. E. (2000). Simulated feedforward neural network coordination of hand grasp and wrist angle in a neuroprosthesis. IEEE Trans. Rehabil. Eng. 8, 297-304. doi: 10.1109/86.867871

Andersen, R. A., Musallam, S., and Pesaran, B. (2004). Selecting the signals for a brain-machine interface. Curr. Opin. Neurobiol. 14, 720-726. doi: 10.1016/j.conb.2004.10.005

Angeli, C. A., Edgerton, V. R., Gerasimenko, Y. P., and Harkema, S. J. (2014). Altering spinal cord excitability enables voluntary movements after chronic 
complete paralysis in humans. Brain 137, 1394-1409. doi: 10.1093/brain/ awu038

Avestruz, A.-T., Santa, W., Carlson, D., Jensen, R., Stanslaski, S., Helfenstine, A., et al. (2008). A $5 \mathrm{uW} /$ channel spectral analysis IC for chronic bidirectional brain-machine interfaces. IEEE J. Solid-State Circuits 43, 3006-3024. doi: 10.1109/JSSC.2008.2006460

Bai, Q., and Wise, K. D. (2001). Single-unit neural recording with active microelectrode arrays. IEEE Trans. Biomed. Eng. 48, 911-920. doi: 10.1109/10.936367

Bamford, J. A. (2005). Intraspinal microstimulation preferentially recruits fatigueresistant muscle fibres and generates gradual force in rat. J. Physiol. 569, 873-884. doi: 10.1113/jphysiol.2005.094516

Bamford, J. A., and Mushahwar, V. K. (2011). Intraspinal microstimulation for the recovery of function following spinal cord injury. Prog. Brain Res. 227-239. doi: 10.1016/B978-0-444-53815-4.00004-2

Bamford, J. A., Todd, K. G., and Mushahwar, V. K. (2010). The effects of intraspinal microstimulation on spinal cord tissue in the rat. Biomaterials 31, 5552-5563. doi: 10.1016/j.biomaterials.2010.03.051

Barron, A. R. (1993). Universal approximation bounds for superpositions of a sigmoidal function. IEEE Trans. Inform. Theory 39, 930-945. doi: $10.1109 / 18.256500$

Basu, I., Graupe, D., Tuninetti, D., Shukla, P., Slavin, K. V., Metman, L. V., et al. (2013). Pathological tremor prediction using surface electromyogram and acceleration: potential use in "ON-OFF" demand driven deep brain stimulator design. J. Neural Eng. 10:036019. doi: 10.1088/1741-2560/10/3/036019

Bean, B. P. (2007). The action potential in mammalian central neurons. Nat. Rev. Neurosci. 8, 451-465. doi: 10.1038/nrn2148

Behrend, C. E., Cassim, S. M., and Pallone, M. J. (2009). Toward feedback controlled deep brain stimulation: dynamics of glutamate release in the subthalamic nucleus in rats. J. Neurosci. Methods. 180, 278-289. doi: 10.1016/j.jneumeth.2009.04.001

Bhadra, N., and Peckham, P. H. (1997). Peripheral nerve stimulation for restoration of motor function. J. Clin. Neurophysiol. 14, 378-393. doi: 10.1097/00004691199709000-00004

Bhadra, N., Peckham, P. H., and Keith, M. W. (2002). Implementation of an implantable joint-angle transducer. J. Rehabil. Res. Dev. 39, 411-422.

Bîrlea, S. I., Breen, P. P., Corley, G. J., Bîrlea, N. M., Quondamatteo, F., and ÓLaighin, G. (2014). Changes in the electrical properties of the electrodeskin-underlying tissue composite during a week-long programme of neuromuscular electrical stimulation. Physiol. Meas. 35, 231-252. doi: 10.1088/0967$3334 / 35 / 2 / 231$

Bizzi, E., Mussa-Ivaldi, F. A., and Giszter, S. (1991). Computations underlying the execution of movement: a biological perspective. Science 253, 287-291. doi: 10.1126/science. 1857964

Blaha, C. D., and Phillips, A. G. (1996). A critical assessment of electrochemical procedures applied to the measurement of dopamine and its metabolites during drug-induced and species-typical behaviours. Behav. Pharmacol. 7, 675-708. doi: 10.1097/00008877-199611000-00014

Bledsoe, J. M., Kimble, C. J., Covey, D. P., Blaha, C. D., Agnesi, F., Mohseni, P., et al. (2009). Development of the wireless instantaneous neurotransmitter concentration system for intraoperative neurochemical monitoring using fast-scan cyclic voltammetry. J. Neurosurg. 111, 712-723. doi: 10.3171/2009.3. JNS081348

Bogataj, U., Gros, N., Malezic, M., Kelih, B., Kljajiæ, M., and Acimoviæ, R. (1989). Restoration of gait during two to three weeks of therapy with multichannel electrical stimulation. Phys. Ther. 69, 319-327.

Boom, H. B., Mulder, A. J., and Veltink, P. H. (1993). Fatigue during functional neuromuscular stimulation. Prog. Brain Res. 97, 409-418. doi: 10.1016/S00796123(08)62300-6

Branner, A., Stein, R. B., and Normann, R. A. (2001). Selective stimulation of cat sciatic nerve using an array of varying-length microelectrodes. J. Neurophysiol. 85, 1585-1594.

Brill, N., Polasek, K., Oby, E., Ethier, C., Miller, L., and Tyler, D. (2009). Nerve cuff stimulation and the effect of fascicular organization for hand grasp in nonhuman primates. Conf. Proc. IEEE Eng. Med. Biol. Soc. 2009, 1557-1560. doi: 10.1109/IEMBS.2009.5332395

Bronte-Stewart, H., Barberini, C., Koop, M. M., Hill, B. C., Henderson, J. M., and Wingeier, B. (2009). The STN beta-band profile in Parkinson's disease is stationary and shows prolonged attenuation after deep brain stimulation. Exp. Neurol. 215, 20-28. doi: 10.1016/j.expneurol.2008.09.008
Buzsáki, G., Anastassiou, C. A., and Koch, C. (2012). The origin of extracellular fields and currents-EEG, ECoG, LFP and spikes. Nat. Rev. Neurosci. 13, 407-420. doi: 10.1038/nrn3241

Buzsáki, G., Leung, L. W., and Vanderwolf, C. H. (1983). Cellular bases of hippocampal EEG in the behaving rat. Brain Res. 287, 139-171. doi: 10.1016/01650173(83)90037-1

Caldwell, C. W., and Reswick, J. B. (1975). A percutaneous wire electrode for chronic research use. IEEE Trans. Biomed. Eng. 22, 429-432. doi: 10.1109/TBME.1975.324516

Carmena, J. (2012). Becoming bionic: the new brain-machine interfaces that exploit plasticity of the brain may allow people to control prosthetic devices in a natural way. IEEE Spectr. 24-29. doi: 10.1109/MSPEC.2012.6156860

Carter, R. R., and Houk, J. C. (1993). Multiple single-unit recordings from the CNS using thin-film electrode arrays. IEEE Trans. Rehab. Eng. 1, 175-184. doi: $10.1109 / 86.279266$

Chadwick, E. K., Blana, D., Simeral, J. D., Lambrecht, J., Kim, S. P., Cornwell, A. S., et al. (2011). Continuous neuronal ensemble control of simulated arm reaching by a human with tetraplegia. J. Neural Eng. 8:034003. doi: 10.1088/17412560/8/3/034003

Chakraborty, K., Mehrotra, K., Mohan, C. K., and Ranka, S. (1992). Forecasting the behavior of multivariate time series using neural networks. Neural Netw. 5 , 961-970. doi: 10.1016/S0893-6080(05)80092-9

Chang, G. C., Liao, G. D., Luh, J. J., Lai, J. S., Cheng, C. K., and Kuo, T. S. (1996). "Application of neural network-based controller for the knee-joint position control with quadriceps stimulation," in IEEE (Amsterdam), 455-456.

Chang, G. C., Luh, J. J., Liao, G. D., Lai, J. S., Cheng, C. K., Kuo, B. L., et al. (1997) A neuro-control system for the knee joint position control with quadriceps stimulation. IEEE Trans. Rehabil. Eng. 5, 2-11. doi: 10.1109/86.559344

Chang, S.-Y., Kim, I., Marsh, M. P., Jang, D. P., Hwang, S.-C., Van Gompel, J. J., et al. (2012). Wireless fast-scan cyclic voltammetry to monitor adenosine in patients with essential tremor during deep brain stimulation. Mayo Clin. Proc. 87, 760-765. doi: 10.1016/j.mayocp.2012.05.006

Chao, Z. C., Nagasaka, Y., and Fujii, N. (2010). Long-term asynchronous decoding of arm motion using electrocorticographic signals in monkeys. Front. Neuroeng 3:3. doi: $10.3389 /$ fneng.2010.00003

Chen, D., Apple, D. F., Hudson, L. M., and Bode, R. (1999). Medical complications during acute rehabilitation following spinal cord injury-current experience of the Model Systems. Arch. Phys. Med. Rehabil. 80, 1397-1401.

Chen, J. J., Yu, N. Y., Huang, D. G., Ann, B. T., and Chang, G. C. (1997). Applying fuzzy logic to control cycling movement induced by functional electrical stimulation. IEEE Trans. Rehabil. Eng. 5, 158-169. doi: 10.1109/86.593285

Cheung, K. C. (2007). Implantable microscale neural interfaces. Biomed Microdevices 9, 923-938. doi: 10.1007/s10544-006-9045-Z

Cheung, K. C., Renaud, P., Tanila, H., and Djupsund, K. (2007). Flexible polyimide microelectrode array for in vivo recordings and current source density analysis. Biosens. Bioelectron. 22, 1783-1790. doi: 10.1016/j.bios.2006.08.035

Chizek, H. J., Kobetic, R., and Marsolais, E. B. (1988). Control of Functional Neuromuscular Stimulation Systems for Standing and Locomotion in Paraplegics. Washington, DC: IEEE.

Collinger, J. L., Vinjamuri, R., Degenhart, A. D., Weber, D. J., Sudre, G. P., Boninger, M. L., et al. (2014). Motor-related brain activity during action observation: a neural substrate for electrocorticographic brain-computer interfaces after spinal cord injury. Front. Integr. Neurosci. 8:17. doi: 10.3389/fnint.2014.00017

Crago, P. E., Peckham, P. H., and Thrope, G. B. (1980). Modulation of muscle force by recruitment during intramuscular stimulation. IEEE Trans. Biomed. Eng. 27, 679-684. doi: 10.1109/TBME.1980.326592

Creasey, G. H., and Craggs, M. D. (2012). Functional electrical stimulation for bladder, bowel, and sexual function. Handb. Clin. Neurol. 109, 247-257. doi: 10.1016/B978-0-444-52137-8.00015-2

Daly, J. J., Cheng, R., Rogers, J., Litinas, K., Hrovat, K., and Dohring, M. (2009). Feasibility of a new application of noninvasive Brain Computer Interface (BCI): a case study of training for recovery of volitional motor control after stroke. J. Neurol. Phys. Ther. 33, 203-211. doi: 10.1097/NPT.0b013e3181clfc0b

Davoodi, R., and Andrews, B. J. (1998). Computer simulation of FES standing up in paraplegia: a self-adaptive fuzzy controller with reinforcement learning. IEEE Trans. Rehabil. Eng. 6, 151-161. doi: 10.1109/86.681180

Davoodi, R., and Andrews, B. J. (1999). Optimal control of FES-assisted standing up in paraplegia using genetic algorithms. Med. Eng. Phys. 21, 609-617. doi: 10.1016/S1350-4533(99)00093-4 
Demuth, H., and Beale, M. (2000). Neural Network Toolbox: For Use with MATLAB. Natick, MA: The Mathworks, Inc.

DeVivo, M. J. (2012). Epidemiology of traumatic spinal cord injury: trends and future implications. Spinal Cord 50, 365-372. doi: 10.1038/sc.2011.178

Do, A. H., Wang, P. T., King, C. E., Abiri, A., and Nenadic, Z. (2011). Brain-computer interface controlled functional electrical stimulation system for ankle movement. J. Neuroeng. Rehabil. 8:49. doi: 10.1186/17430003-8-49

Dominici, N., Keller, U., Vallery, H., Friedli, L., van den Brand, R., Starkey, M. L., et al. (2012). Versatile robotic interface to evaluate, enable and train locomotion and balance after neuromotor disorders. Nat. Med. 18, 1142-1147. doi: 10.1038/nm.2845

Durfee, W. K. (1989). Task-based methods for evaluating electrically stimulated antagonist muscle controllers. IEEE Trans. Biomed. Eng. 36, 309-321. doi: $10.1109 / 10.19852$

Etlin, A., Finkel, E., Cherniak, M., Lev-Tov, A., and Anglister, L. (2014). The motor output of hindlimb innervating segments of the spinal cord is modulated by cholinergic activation of rostrally projecting sacral relay neurons. J. Mol. Neurosci. 53, 517-524. doi: 10.1007/s12031-014-0351-2

Fifer, M. S., Acharya, S., Benz, H. L., Mollazadeh, M., Crone, N. E., and Thakor, N. V. (2012). Toward electrocorticographic control of a dexterous upper limb prosthesis: building brain-machine interfaces. IEEE Pulse 3, 38-42. doi: 10.1109/MPUL.2011.2175636

Fisher, L. E., Miller, M. E., Bailey, S. N., Davis, J. A., Anderson, J. S., Rhode, L., et al. (2008). Standing after spinal cord injury with four-contact nerve-cuff electrodes for quadriceps stimulation. IEEE Trans. Neural Syst. Rehabil. Eng. 16, 473-478. doi: 10.1109/TNSRE.2008.2003390

Fisher, L. E., Tyler, D. J., Anderson, J. S., and Triolo, R. J. (2009). Chronic stability and selectivity of four-contact spiral nerve-cuff electrodes in stimulating the human femoral nerve. J. Neural Eng. 6:046010. doi: 10.1088/17412560/6/4/046010

Fitzgerald, P. J. (2014). Is elevated norepinephrine an etiological factor in some cases of Parkinson's disease? Med. Hypotheses 82, 462-469. doi: 10.1016/j.mehy.2014.01.026

Fraix, V., Houeto, J.-L., Lagrange, C., Le Pen, C., Krystkowiak, P., Guehl, D., et al. (2006). Clinical and economic results of bilateral subthalamic nucleus stimulation in Parkinson's disease. J. Neurol. Neurosurg. Psychiatr. 77, 443-449. doi: 10.1136/jnnp.2005.077677

Fujita, K., Shiga, K., and Takahashi, H. (1998). "Learning control of hand posture with neural network in FES for hemiplegics," in IEEE (Hong Kong), 2588-2589.

Funahashi, K.-I. (1989). On the approximate realization of continuous mappings by neural networks. Neural Netw. 2, 183-192. doi: 10.1016/08936080(89)90003-8

Galvani, L., and Aldini, G. (1792). De Viribus Electricitatis in Motu Musculari Commentarius. Bologna: Ex typographia Instituti Scientiarum.

Gan, L. S., Ravid, E., Kowalczewski, J. A., Olson, J. L., Morhart, M., and Prochazka, A. (2012). First permanent implant of nerve stimulation leads activated by surface electrodes, enabling hand grasp and release: the stimulus router neuroprosthesis. Neurorehabil. Neural Repair 26, 335-343. doi: $10.1177 / 1545968311420443$

Georgopoulos, A. P., Schwartz, A. B., and Kettner, R. E. (1986). Neuronal population coding of movement direction. Science 233, 1416-1419. doi: 10.1126/science. 3749885

Gerasimenko, Y., Roy, R. R., and Edgerton, V. R. (2008). Epidural stimulation: comparison of the spinal circuits that generate and control locomotion in rats, cats and humans. Exp. Neurol. 209, 417-425. doi: 10.1016/j.expneurol.2007.07.015

Giszter, S. F., Mussa-Ivaldi, F. A., and Bizzi, E. (1993). Convergent force fields organized in the frog's spinal cord. J. Neurosci. 13, 467-491.

Glenn, W. W., Holcomb, W. G., Shaw, R. K., Hogan, J. F., and Holschuh, K. R. (1976). Long-term ventilatory support by diaphragm pacing in quadriplegia. Ann. Surg. 183, 566-577. doi: 10.1097/00000658-197605000-00014

Gorman, P. H. (2000). An update on functional electrical stimulation after spinal cord injury. Neurorehabil. Neural Repair 14, 251-263.

Grant, P. F., and Lowery, M. M. (2013). Simulation of cortico-basal ganglia oscillations and their suppression by closed loop deep brain stimulation. IEEE Trans. Neural Syst. Rehabil. Eng. 21, 584-594. doi: 10.1109/TNSRE.2012.2202403

Graupe, D., and Kordylewski, H. (1995). Artificial neural network control of FES in paraplegics for patient responsive ambulation. IEEE Trans. Biomed. Eng. 42, 699-707. doi: 10.1109/10.391169
Griessenauer, C. J., Chang, S.-Y., Tye, S. J., Kimble, C. J., Bennet, K. E., Garris, P. A., et al. (2010). Wireless Instantaneous neurotransmitter concentration system: electrochemical monitoring of serotonin using fast-scan cyclic voltammetry-a proof-of-principle study. J. Neurosurg. 113, 656-665. doi: 10.3171/2010.3.JNS091627

Grobelnik, S. (1973). Functional electrical stimulation-a new hope for paraplegic patients? Bull. Prosthet. Res. 75-102.

Guertin, P. A. (2014). Preclinical evidence supporting the clinical development of central pattern generator-modulating therapies for chronic spinal cord-injured patients. Front. Hum. Neurosci. 8:272. doi: 10.3389/fnhum.2014.00272

Guiraud, D., Stieglitz, T., Koch, K. P., Divoux, J.-L., and Rabischong, P. (2006). An implantable neuroprosthesis for standing and walking in paraplegia: 5-year patient follow-up. J. Neural Eng. 3, 268-275. doi: 10.1088/1741-2560/ $3 / 4 / 003$

Gustafsson, B., and Jankowska, E. (1976). Direct and indirect activation of nerve cells by electrical pulses applied extracellularly. J. Physiol. 258, 33-61.

Hachmann, J. T., Jeong, J. H., Grahn, P. J., Mallory, G. W., Evertz, L. Q., Bieber, A. J., et al. (2013). Large animal model for development of functional restoration paradigms using epidural and intraspinal stimulation. PLoS ONE 8:e81443. doi: 10.1371/journal.pone.0081443

Hambrecht, F. T. (1992). "A brief history of neural prostheses for motor control of paralyzed extremeties," in Neural Prostheses: Replacing Motor Function After Disease or Disability, eds R. B. Stein, P. H. Peckham and D. Popović (Oxford, UK: Oxford University Press), 3-14.

Harkema, S., Gerasimenko, Y., Hodes, J., Burdick, J., Angeli, C., Chen, Y., et al. (2011). Effect of epidural stimulation of the lumbosacral spinal cord on voluntary movement, standing, and assisted stepping after motor complete paraplegia: a case study. Lancet 377, 1938-1947. doi: 10.1016/S0140-6736(11)60547-3 Hassoun, M. H. (1995). Fundamentals of Artificial Neural Networks. Google Books. Hayashibe, M., Zhang, Q., Guiraud, D., and Fattal, C. (2011). Evoked EMGbased torque prediction under muscle fatigue in implanted neural stimulation. J. Neural Eng. 8:064001. doi: 10.1088/1741-2560/8/6/064001

Hirokawa, S., Grimm, M., Le, T., Solomonow, M., Baratte, R. V., Shoji, H., et al. (1990). Energy consumption in paraplegic ambulation using the reciprocating gait orthosis and electric stimulation of the thigh muscles. Arch. Phys. Med. Rehabil. 71, 687-694.

Hobby, J., Taylor, P. N., and Esnouf, J. (2001). Restoration of tetraplegic hand function by use of the neurocontrol freehand system. J. Hand Surg. Br. 26, 459-464. doi: 10.1054/jhsb.2001.0587

Hochberg, L. R., Bacher, D., Jarosiewicz, B., Masse, N. Y., Simeral, J. D., Vogel, J., et al. (2012). Reach and grasp by people with tetraplegia using a neurally controlled robotic arm. Nature 485, 372-375. doi: 10.1038/nature11076

Hochberg, L. R., Serruya, M. D., Friehs, G. M., Mukand, J. A., Saleh, M., Caplan, A. H., et al. (2006). Neuronal ensemble control of prosthetic devices by a human with tetraplegia. Nature 442, 164-171. doi: 10.1038/nature04970

Hoffer, J. A., Stein, R. B., Haugland, M. K., Sinkjaer, T., Durfee, W. K., Schwartz, A. B., et al. (1996). Neural signals for command control and feedback in functional neuromuscular stimulation: a review. J. Rehabil. Res. Dev. 33, 145-157.

Holinski, B. J., Everaert, D. G., Mushahwar, V. K., and Stein, R. B. (2013). Realtime control of walking using recordings from dorsal root ganglia. J. Neural Eng. 10:056008. doi: 10.1088/1741-2560/10/5/056008

Holinski, B. J., Mazurek, K. A., Everaert, D. G. K., Stein, R. B., and Mushahwar, V. K. (2011). Restoring stepping after spinal cord injury using intraspinal microstimulation and novel control strategies. Conf. Proc. IEEE Eng. Med. Biol. Soc. 2011 , 5798-5801. doi: 10.1109/IEMBS.2011.6091435

Hornik, K., Stinchcombe, M., and White, H. (1989). Multilayer feedforward networks are universal approximators. Neural Netw. 2, 359-366. doi: 10.1016/08936080(89)90020-8

Hughes, B. W., Kusner, L. L., and Kaminski, H. J. (2006). Molecular architecture of the neuromuscular junction. Muscle Nerve 33, 445-461. doi: 10.1002/mus.20440

Jackson, A., Mavoori, J., and Fetz, E. E. (2006). Long-term motor cortex plasticity induced by an electronic neural implant. Nature 444, 56-60. doi: 10.1038 /nature05226

Jackson, A., and Zimmermann, J. B. (2012). Neural interfaces for the brain and spinal cord-restoring motor function. Nat. Rev. Neurol. 8, 690-699. doi: 10.1038/nrneurol.2012.219

Jankowska, E., and Roberts, W. J. (1972a). An electrophysiological demonstration of the axonal projections of single spinal interneurons in the cat. J. Physiol. 222, 597-622. 
Jankowska, E., and Roberts, W. J. (1972b). Synaptic actions of single interneurones mediating reciprocal Ia inhibition of motorneurones. J. Physiol. 222, 623-642.

Jilge, B., Minassian, K., Rattay, F., Pinter, M. M., Gerstenbrand, F., Binder, H., et al. (2004). Initiating extension of the lower limbs in subjects with complete spinal cord injury by epidural lumbar cord stimulation. Exp. Brain Res. 154, 308-326. doi: 10.1007/s00221-003-1666-3

Jonić, S., Janković, T., Gajiæ, V., and Popović, D. (1999). Three machine learning techniques for automatic determination of rules to control locomotion. IEEE Trans. Biomed. Eng. 46, 300-310. doi: 10.1109/10.748983

Kaneyuki, T., Hogan, J. F., Glenn, W. W., and Holcomb, W. G. (1977). Diaphragm pacing. Evaluation of current waveforms for effective ventilation. J. Thorac. Cardiovasc. Surg. 74, 109-115.

Karniel, A., and Inbar, G. F. (2000). Human motor control: learning to control a time-varying, nonlinear, many-to-one system. IEEE Trans. Syst. Man Cybern. 30, 1-11. doi: 10.1109/5326.827449

Kasten, M. R., Sunshine, M. D., Secrist, E. S., Horner, P. J., and Moritz, C. T. (2013). Therapeutic intraspinal microstimulation improves forelimb function after cervical contusion injury. J. Neural Eng. 10:044001. doi: 10.1088/17412560/10/4/044001

Kent, A. R., and Grill, W. M. (2013). Model-based analysis and design of nerve cuff electrodes for restoring bladder function by selective stimulation of the pudendal nerve. J. Neural Eng. 10:036010. doi: 10.1088/1741-2560/10/3/036010

Kilgore, K. L., Hoyen, H. A., Bryden, A. M., Hart, R. L., Keith, M. W., and Peckham, P. H. (2008). An implanted upper-extremity neuroprosthesis using myoelectric control. J. Hand Surg. Am. 33, 539-550. doi: 10.1016/j.jhsa.2008.01.007

Kilgore, K. L., Peckham, P., and Keith, M. W. (2009). Twenty year experience with implanted neuroprostheses. Conf. Proc. IEEE Eng. Med. Biol. Soc. 2009, 7212-7215. doi: 10.1109/IEMBS.2009.5335272

Knutson, J. S., Naples, G. G., Peckham, P. H., and Keith, M. W. (2002). Electrode fracture rates and occurrences of infection and granuloma associated with percutaneous intramuscular electrodes in upper-limb functional electrical stimulation applications. J. Rehabil. Res. Dev. 39, 671-683.

Kobravi, H.-R., and Erfanian, A. (2012). A decentralized adaptive fuzzy robust strategy for control of upright standing posture in paraplegia using functional electrical stimulation. Med. Eng. Phys. 34, 28-37. doi: 10.1016/j.medengphy.2011.06.013

Kostov, A., Andrews, B. J., Popović, D. B., Stein, R. B., and Armstrong, W. W. (1995). Machine learning in control of functional electrical stimulation systems for locomotion. IEEE Trans. Biomed. Eng. 42, 541-551. doi: 10.1109/10. 387193

Kowalski, K. C., He, B. D., and Srinivasan, L. (2013). Dynamic analysis of naive adaptive brain-machine interfaces. Neural Comput. 25, 2373-2420. doi: 10.1162/NECO_a_00484

Krajl, A., Bajd, T., Turk, R., and Benko, H. (1986). Posture switching for prolonging functional electrical stimulation standing in paraplegic patients. Paraplegia 24, 221-230. doi: 10.1038/sc.1986.31

Kralj, A., Bajd, T., and Turk, R. (1988). Enhancement of gait restoration in spinal injured patients by functional electrical stimulation. Clin. Orthop. Relat. Res. 233, 34. doi: 10.1097/00003086-198808000-00006

Kralj, A. R., and Bajd, T. (1989). Functional Electrical Stimulation: Standing and Walking After Spinal Cord Injury. Google Books.

Lan, N., Feng, H. Q., and Crago, P. E. (1994). Neural network generation of muscle stimulation patterns for control of arm movements. IEEE Trans. Rehab. Eng. 2, 213-224. doi: 10.1109/86.340877

Langhals, N. B., and Kipke, D. R. (2009). Validation of a novel three-dimensional electrode array within auditory cortex. Conf. Proc. IEEE Eng. Med. Biol. Soc. 2009, 2066-2069. doi: 10.1109/IEMBS.2009.5333958

Lau, B., Guevremont, L., and Mushahwar, V. K. (2007). Strategies for generating prolonged functional standing using intramuscular stimulation or intraspinal microstimulation. IEEE Trans. Neural Syst. Rehabil. Eng. 15, 273-285. doi: 10.1109/TNSRE.2007.897030

Lavrov, I., Courtine, G., Dy, C. J., van den Brand, R., Fong, A. J., Gerasimenko, Y., et al. (2008). Facilitation of stepping with epidural stimulation in spinal rats: role of sensory input. J. Neurosci. 28, 7774-7780. doi: 10.1523/JNEUROSCI.1069-08.2008

Lee, K. H., Blaha, C. D., Garris, P. A., Mohseni, P., Horne, A. E., Bennet, K. E., et al. (2009). Evolution of deep brain stimulation: human electrometer and smart devices supporting the next generation of therapy. Neuromodulation 12, 85-103. doi: $10.1111 / j .1525-1403.2009 .00199 . x$
Lee, K. H., Blaha, C. D., Harris, B. T., Cooper, S., Hitti, F. L., Leiter, J. C., et al. (2006). Dopamine efflux in the rat striatum evoked by electrical stimulation of the subthalamic nucleus: potential mechanism of action in Parkinson's disease. Eur. J. Neurosci. 23, 1005-1014. doi: 10.1111/j.1460-9568.2006.04638.x

Lee, K. H., Chang, S.-Y., Roberts, D. W., and Kim, U. (2004). Neurotransmitter release from high-frequency stimulation of the subthalamic nucleus. J. Neurosurg. 101, 511-517. doi: 10.3171/jns.2004.101.3.0511

Lemay, M. A., Galagan, J. E., Hogan, N., and Bizzi, E. (2001). Modulation and vectorial summation of the spinalized frog's hindlimb end-point force produced by intraspinal electrical stimulation of the cord. IEEE Trans. Neural Syst. Rehabil. Eng. 9, 12-23. doi: 10.1109/7333.918272

Lemay, M. A., Grasse, D., and Grill, W. M. (2009). Hindlimb Endpoint forces predict movement direction evoked by intraspinal microstimulation in cats. IEEE Trans. Neural Syst. Rehabil. Eng. 17, 379-389. doi: 10.1109/TNSRE.2009. 2023295

Lemay, M. A., and Grill, W. M. (2004). Modularity of motor output evoked by intraspinal microstimulation in cats. J. Neurophysiol. 91, 502-514. doi: 10.1152/jn.00235.2003

Lenehan, B., Street, J., Kwon, B. K., Noonan, V., Zhang, H., Fisher, C. G., et al. (2012). The epidemiology of traumatic spinal cord injury in British Columbia, Canada. Spine 37, 321-329. doi: 10.1097/BRS.0b013e31822e5ff8

Leuthardt, E. C., Schalk, G., Wolpaw, J. R., Ojemann, J. G., and Moran, D. W. (2004). A brain-computer interface using electrocorticographic signals in humans. J. Neural Eng. 1, 63-71. doi: 10.1088/1741-2560/1/2/001

Lobel, D. A., and Lee, K. H. (2014). Brain machine interface and limb reanimation technologies: restoring function after spinal cord injury through development of a bypass system. Mayo Clin. Proc. 89, 708-714. doi: 10.1016/j.mayocp.2014.02.003

Logothetis, N. K. (2003a). MR imaging in the non-human primate: studies of function and of dynamic connectivity. Curr. Opin. Neurobiol. 13, 630-642. doi: 10.1016/j.conb.2003.09.017

Logothetis, N. K. (2003b). The underpinnings of the BOLD functional magnetic resonance imaging signal. J. Neurosci. 23, 3963-3971.

Lujan, J. L., and Crago, P. E. (2009). Automated optimal coordination of multipleDOF neuromuscular actions in feedforward neuroprostheses. IEEE Trans. Biomed. Eng. 56, 179-187. doi: 10.1109/TBME.2008.2002159

MacDonald, A. A., Monchi, O., Seergobin, K. N., Ganjavi, H., Tamjeedi, R., and MacDonald, P. A. (2013). Parkinson's disease duration determines effect of dopaminergic therapy on ventral striatum function. Mov. Disord. 28, 153-160. doi: $10.1002 / \mathrm{mds} .25152$

Mahajan, P., Jaffe, D. M., Olsen, C. S., Leonard, J. R., Nigrovic, L. E., Rogers, A. J., et al. (2013). Spinal cord injury without radiologic abnormality in children imaged with magnetic resonance imaging. J. Trauma Acute Care Surg. 75, 843-847. doi: 10.1097/TA.0b013e3182a74abd

Malezic, M., Stanic, U., Kljajić, M., Acimović, R., Krajnik, J., Gros, N., et al. (1984). Multichannel electrical stimulation of gait in motor disabled patients. Orthopedics 7, 1187-1195.

Mangold, S., Keller, T., Curt, A., and Dietz, V. (2005). Transcutaneous functional electrical stimulation for grasping in subjects with cervical spinal cord injury. Spinal Cord 43, 1-13. doi: 10.1038/sj.sc.3101644

Marino, R. J., Barros, T., Biering-Sorensen, F., Burns, S. P., Donovan, W. H., Graves, D. E., et al. (2003). International standards for neurological classification of spinal cord injury. J. Spinal Cord Med. 26(Suppl. 1), S50-S56.

Marsolais, E. B., and Kobetic, R. (1986). Implantation techniques and experience with percutaneous intramuscular electrodes in the lower extremities. J. Rehabil. Res. Dev. 23, 1-8.

McDonald, J. W., and Sadowsky, C. (2002). Spinal-cord injury. Lancet 359, 417-425. doi: 10.1016/S0140-6736(02)07603-1

McDonnall, D., Clark, G. A., and Normann, R. A. (2004). Interleaved, multisite electrical stimulation of cat sciatic nerve produces fatigue-resistant, ripplefree motor responses. IEEE Trans. Neural Syst. Rehabil. Eng. 12, 208-215. doi: 10.1109/TNSRE.2004.828425

Meriney, S. D., and Dittrich, M. (2013). Organization and function of transmitter release sites at the neuromuscular junction. J. Physiol. 591, 3159-3165. doi: 10.1113/jphysiol.2012.248625

Miller, K. J., Schalk, G., Fetz, E. E., den Nijs, M., Ojemann, J. G., and Rao, R. P. N. (2010). Cortical activity during motor execution, motor imagery, and imagery-based online feedback. Proc. Natl. Acad. Sci. U.S.A. 107, 4430-4435. doi: 10.1073/pnas.0913697107 
Minassian, K., Jilge, B., Rattay, F., Pinter, M. M., Binder, H., Gerstenbrand, F., et al. (2004). Stepping-like movements in humans with complete spinal cord injury induced by epidural stimulation of the lumbar cord: electromyographic study of compound muscle action potentials. Spinal Cord 42, 401-416. doi: 10.1038/sj.sc.3101615

Minassian, K., Persy, I., Rattay, F., Pinter, M. M., Kern, H., and Dimitrijevic, M. R. (2007). Human lumbar cord circuitries can be activated by extrinsic tonic input to generate locomotor-like activity. Hum. Mov. Sci. 26, 275-295. doi: 10.1016/j.humov.2007.01.005

Mirovsky, Y., Shalmon, E., Blankstein, A., and Halperin, N. (2005). Complete paraplegia following gunshot injury without direct trauma to the cord. Spine 30, 2436-2438. doi: 10.1097/01.brs.0000184588.54710.61

Molinuevo, J. L., Valldeoriola, F., Tolosa, E., Rumia, J., Valls-Sole, J., Roldan, H., et al. (2000). Levodopa withdrawal after bilateral subthalamic nucleus stimulation in advanced Parkinson disease. Arch. Neurol. 57, 983-988. doi: 10.1001/archneur.57.7.983

Moran, D. (2010). Evolution of brain-computer interface: action potentials, local field potentials and electrocorticograms. Curr. Opin. Neurobiol. 20, 741-745. doi: 10.1016/j.conb.2010.09.010

Moritz, C. T., Lucas, T. H., Perlmutter, S. I., and Fetz, E. E. (2007). Forelimb movements and muscle responses evoked by microstimulation of cervical spinal cord in sedated monkeys. J. Neurophysiol. 97, 110-120. doi: 10.1152/jn.00414.2006

Moritz, C. T., Perlmutter, S. I., and Fetz, E. E. (2008). Direct control of paralysed muscles by cortical neurons. Nature 456, 639-642. doi: 10.1038/nature07418

Moro, E., Scerrati, M., Romito, L. M., Roselli, R., Tonali, P., and Albanese, A. (1999). Chronic subthalamic nucleus stimulation reduces medication requirements in Parkinson's disease. Neurology 53, 85-90. doi: 10.1212/WNL.53.1.85

Müller-Putz, G. R., Scherer, R., Pfurtscheller, G., and Rupp, R. (2005). EEG-based neuroprosthesis control: a step towards clinical practice. Neurosci. Lett. 382, 169-174. doi: 10.1016/j.neulet.2005.03.021

Musallam, S., Corneil, B. D., Greger, B., Scherberger, H., and Andersen, R. A. (2004). Cognitive control signals for neural prosthetics. Science 305, 258-262. doi: 10.1126/science. 1097938

Mushahwar, V. (2000). Spinal cord microstimulation generates functional limb movements in chronically implanted cats. Exp. Neurol. 163, 422-429. doi: 10.1006/exnr.2000.7381

Mushahwar, V. K., Gillard, D. M., Gauthier, M. J. A., and Prochazka, A. (2002). Intraspinal micro stimulation generates locomotor-like and feedbackcontrolled movements. IEEE Trans. Neural Syst. Rehabil. Eng. 10, 68-81. doi: 10.1109/TNSRE.2002.1021588

Mushahwar, V. K., and Horch, K. W. (1997). Proposed specifications for a lumbar spinal cord electrode array for control of lower extremities in paraplegia. IEEE Trans. Rehabil. Eng. 5, 237-243. doi: 10.1109/86.623015

Mushahwar, V. K., and Horch, K. W. (2000a). Muscle recruitment through electrical stimulation of the lumbo-sacral spinal cord. IEEE Trans. Rehabil. Eng. 8, 22-29. doi: 10.1109/86.830945

Mushahwar, V. K., and Horch, K. W. (2000b). Selective activation of muscle groups in the feline hindlimb through electrical microstimulation of the ventral lumbosacral spinal cord. IEEE Trans. Rehabil. Eng. 8, 11-21. doi: 10.1109/86.830944

Mushahwar, V. K., Jacobs, P. L., Normann, R. A., Triolo, R. J., and Kleitman, N. (2007). New functional electrical stimulation approaches to standing and walking. J. Neural Eng. 4, S181-S197. doi: 10.1088/1741-2560/4/3/S05

Narendra, K. S. (1990). Neural Networks for Control.-Google Books.

Narendra, K. S. (1996). Neural networks for control theory and practice. Proc. IEEE 84, 1385-1406. doi: 10.1109/5.537106

Narendra, K. S., and Parthasarathy, K. (1990). Identification and control of dynamical systems using neural networks. IEEE Trans. Neural Netw. 1, 4-27. doi: $10.1109 / 72.80202$

Nataraj, R., Audu, M. L., and Triolo, R. J. (2013). Center of mass acceleration feedback control of standing balance by functional neuromuscular stimulation against external postural perturbations. IEEE Trans. Biomed. Eng. 60, 10-19. doi: 10.1109/TBME.2012.2218601

National Institute of Neurological Disorders and Stroke. (2013). National Institute of Neurological Disorders and Stroke. National Institutes of Health. Available online at: http://www.ninds.nih.gov/disorders/sci/detail_sci.htm (Accessed May 30, 2014).

National Spinal Cord Injury Statistical Center. (2013). Spinal cord injury facts and figures at a glance. J. Spinal Cord Med. 36, 1-2. doi: $10.1179 / 1079026813 Z .000000000136$
Nicolas-Alonso, L. F., and Gomez-Gil, J. (2012). Brain computer interfaces, a review. Sensors (Basel) 12, 1211-1279. doi: 10.3390/s120201211

Niddam, D. M., Graven-Nielsen, T., Arendt-Nielsen, L., and Chen, A. C. (2001). Non-painful and painful surface and intramuscular electrical stimulation at the thenar and hypothenar sites: differential cerebral dynamics of early to late latency SEPs. Brain Topogr. 13, 283-292. doi: 10.1023/A:1011180713285

Nishimura, Y., Perlmutter, S. I., and Fetz, E. E. (2013). Restoration of upper limb movement via artificial corticospinal and musculospinal connections in a monkey with spinal cord injury. Front. Neural Circuits 7, 1-9. doi: 10.3389/fncir.2013.00057

Pang, D., and Wilberger, J. E. (1982). Spinal cord injury without radiographic abnormalities in children. J. Neurosurg. 57, 114-129. doi: 10.3171/jns.1982.57.1.0114

Peckham, P. H., Keith, M. W., Kilgore, K. L., Grill, J. H., Wuolle, K. S., Thrope, G. B., et al. (2001). Efficacy of an implanted neuroprosthesis for restoring hand grasp in tetraplegia: a multicenter study. Arch. Phys. Med. Rehabil. 82, 1380-1388. doi: 10.1053/apmr.2001.25910

Peckham, P. H., and Kilgore, K. L. (2013). Challenges and opportunities in restoring function after paralysis. IEEE Trans. Biomed. Eng. 60, 602-609. doi: 10.1109/TBME.2013.2245128

Peckham, P. H., Kilgore, K. L., Keith, M. W., and Bryden, A. M. (2002). An advanced neuroprosthesis for restoration of hand and upper arm control using an implantable controller. J. Hand Surg. Am. 27, 265-276. doi: 10.1053/jhsu.2002.30919

Peckham, P. H., and Knutson, J. S. (2005). Functional electrical stimulation for neuromuscular applications. Annu. Rev. Biomed. Eng. 7, 327-360. doi: 10.1146/annurev.bioeng.6.040803.140103

Pfurtscheller, G., Müller, G. R., Pfurtscheller, J., Gerner, H. J., and Rupp, R. (2003). "Thought" - control of functional electrical stimulation to restore hand grasp in a patient with tetraplegia. Neurosci. Lett. 351, 33-36. doi: 10.1016/S03043940(03)00947-9

Phillips, W. T., Kiratli, B. J., Sarkarati, M., Weraarchakul, G., Myers, J., Franklin, B. A., et al. (1998). Effect of spinal cord injury on the heart and cardiovascular fitness. Curr. Probl. Cardiol. 23, 641-716. doi: 10.1016/S0146-2806(98)80003-0

Piche, S. W. (1994). Steepest descent algorithms for neural network controllers and filters. IEEE Trans. Neural Netw. 5, 198-212. doi: 10.1109/72.279185

Pikov, V., Bullara, L., and McCreery, D. B. (2007). Intraspinal stimulation for bladder voiding in cats before and after chronic spinal cord injury. J. Neural Eng. 4, 356-368. doi: 10.1088/1741-2560/4/4/002

Polasek, K. H., Schiefer, M. A., Pinault, G. C. J., Triolo, R. J., and Tyler, D. J. (2009). Intraoperative evaluation of the spiral nerve cuff electrode on the femoral nerve trunk. J. Neural Eng. 6:066005. doi: 10.1088/1741-2560/6/6/066005

Polikov, V. S., Tresco, P. A., and Reichert, W. M. (2005). Response of brain tissue to chronically implanted neural electrodes. J. Neurosci. Methods 148, 1-18. doi: 10.1016/j.jneumeth.2005.08.015

Popovic, M. R., Popović, D. B., and Keller, T. (2002). Neuroprostheses for grasping. Neurol. Res. 24, 443-452. doi: 10.1179/016164102101200311

Popovic, M. R., Thrasher, T. A., Adams, M. E., Takes, V., Zivanovic, V., and Tonack, M. I. (2005). Functional electrical therapy: retraining grasping in spinal cord injury. Spinal Cord 44, 143-151. doi: 10.1038/sj.sc.3101822

Posluszny, J. A. Jr., Onders, R., Kerwin, A. J., Weinstein, M. S., Stein, D. M., Knight, J., et al. (2014). Multicenter review of diaphragm pacing in spinal cord injury. J. Trauma Acute Care Surg. 76, 303-310. doi: 10.1097/TA.0000000000000112

Rabischong, E., and Ohanna, F. (1992). Effects of functional electrical stimulation (FES) on evoked muscular output in paraplegic quadriceps muscle. Paraplegia 30, 467-473. doi: 10.1038/sc.1992.100

Rack, P. M., and Westbury, D. R. (1969). The effects of length and stimulus rate on tension in the isometric cat soleus muscle. J. Physiol. 204, 443-460.

Ragnarsson, K. T. (2008). Functional electrical stimulation after spinal cord injury: current use, therapeutic effects and future directions. Spinal Cord 46, 255-274. doi: 10.1038/sj.sc.3102091

Renshaw, B. (1946). Interaction of nerve impulses in the gray matter as a mechanism in central inhibition. Fed. Proc. 5:86.

Riess, J., and Abbas, J. J. (2000). Adaptive neural network control of cyclic movements using functional neuromuscular stimulation. IEEE Trans. Rehabil. Eng. 8, 42-52. doi: $10.1109 / 86.830948$

Riess, J., and Abbas, J. J. (2001). Adaptive control of cyclic movements as muscles fatigue using functional neuromuscular stimulation. IEEE Trans. Neural Syst. Rehabil. Eng. 9, 326-330. doi: 10.1109/7333.948462 
Riess, J. A., and Abbas, J. J. (1999). "Control of cyclic movements as muscles fatigue using functional neuromuscular stimulation," in IEEE (Atlanta, GA), 659.

Roham, M., Halpern, J. M., Martin, H. B., Chiel, H. J., and Mohseni, P. (2007). Diamond microelectrodes and CMOS microelectronics for wireless transmission of fast-scan cyclic voltammetry. Conf. Proc. IEEE Eng. Med. Biol. Soc. 2007, 6044-6047.

Rosa, M., Giannicola, G., Marceglia, S., Fumagalli, M., Barbieri, S., and Priori, A. (2012). Neurophysiology of Deep Brain Stimulation, 1st Edn. Oxford, UK: Elsevier Inc.

Rosin, B., Slovik, M., Mitelman, R., Rivlin-Etzion, M., Haber, S. N., Israel, Z., et al. (2011). Closed-loop deep brain stimulationis superior in ameliorating parkinsonism. Neuron 72, 370-384. doi: 10.1016/j.neuron.2011.08.023

Rowland, L. P. (1991). "Clinical syndromes of the spinal cord and brain stem," in Principles of Neural Science, eds E. Kandel, J. Schwartz, and T. Jessell (East Norwalk, CT: Appleton \& Lange), 711-731.

Saigal, R., Renzi, C., and Mushahwar, V. K. (2004). Intraspinal microstimulation generates functional movements after spinal-cord injury. IEEE Trans. Neural Syst. Rehabil. Eng. 12, 430-440. doi: 10.1109/TNSRE.2004.837754

Saltiel, P., Wyler-Duda, K., D’Avella, A., Tresch, M. C., and Bizzi, E. (2001). Muscle synergies encoded within the spinal cord: evidence from focal intraspinal NMDA iontophoresis in the frog. J. Neurophysiol. 85, 605-619.

Schalk, G., Miller, K. J., Anderson, N. R., Wilson, J. A., Smyth, M. D., Ojemann, J. G., et al. (2008). Two-dimensional movement control using electrocorticographic signals in humans. J. Neural Eng. 5, 75-84. doi: 10.1088/17412560/5/1/008

Schmit, B. D., and Mortimer, J. T. (1997). The tissue response to epimysial electrodes for diaphragm pacing in dogs. IEEE Trans. Biomed. Eng. 44, 921-930. doi: 10.1109/10.634644

Schwartz, A. B., Cui, X. T., Weber, D. J., and Moran, D. W. (2006). Brain-controlled interfaces: movement restoration with neural prosthetics. Neuron 52, 205-220. doi: 10.1016/j.neuron.2006.09.019

Scivoletto, G., Tamburella, F., Laurenza, L., Torre, M., and Molinari, M. (2014). Who is going to walk? A review of the factors influencing walking recovery after spinal cord injury. Front. Hum. Neurosci. 8:141. doi: 10.3389/fnhum.2014. 00141

Scremin, A. E., Kurta, L., Gentili, A., and Wiseman, B. (1999). Increasing muscle mass in spinal cord injured persons with a functional electrical stimulation exercise program. Arch. Phys. Med. Rehabil. 80, 1531-1536. doi: 10.1016/s00039993(99)90326-X

Sekhon, L. H., and Fehlings, M. G. (2001). Epidemiology, demographics, and pathophysiology of acute spinal cord injury. Spine 26, S2-S12. doi: 10.1097/00007632-200112151-00002

Serruya, M. D., Hatsopoulos, N. G., Paninski, L., Fellows, M. R., and Donoghue, J. P. (2002). Instant neural control of a movement signal. Nature 416, 141-142. doi: $10.1038 / 416141 \mathrm{a}$

Shadmehr, R., Smith, M. A., and Krakauer, J. W. (2010). Error correction, sensory prediction, and adaptation in motor control. Annu. Rev. Neurosci. 33, 89-108. doi: 10.1146/annurev-neuro-060909-153135

Sharma, A., Rieth, L., Tathireddy, P., Harrison, R., Oppermann, H., Klein, M., et al. (2011). Long term in vitro functional stability and recording longevity of fully integrated wireless neural interfaces based on the Utah Slant Electrode Array. J. Neural Eng. 8:045004. doi: 10.1088/1741-2560/8/4/045004

Sharma, A., Rieth, L., Tathireddy, P., Harrison, R., and Solzbacher, F. (2010). Long term in vitro stability of fully integrated wireless neural interfaces based on Utah slant electrode array. Appl. Phys. Lett. 96, 73702. doi: 10.1063/1.3318251

Shih, J. J., Krusienski, D. J., and Wolpaw, J. R. (2012). Brain-computer interfaces in medicine. Mayo Clinic Proc. 87, 268-279. doi: 10.1016/j.mayocp.2011.12.008

Shon, Y.-M., Chang, S.-Y., Tye, S. J., Kimble, C. J., Bennet, K. E., Blaha, C. D., et al. (2010a). Comonitoring of adenosine and dopamine using the wireless instantaneous neurotransmitter concentration system: proof of principle. J. Neurosurg. 112, 539-548. doi: 10.3171/2009.7.JNS09787

Shon, Y.-M., Lee, K. H., Goerss, S. J., Kim, I. Y., Kimble, C., Van Gompel, J. J., et al. (2010b). High frequency stimulation of the subthalamic nucleus evokes striatal dopamine release in a large animal model of human DBS neurosurgery. Neurosci. Lett. 475, 136-140. doi: 10.1016/j.neulet.2010.03.060

Sinkjaer, T. (2000). Integrating sensory nerve signals into neural prosthesis devices. Neuromodulation 3, 34-41. doi: 10.1046/j.1525-1403.2000.00035.x

Skarpaas, T. L., and Morrell, M. J. (2009). Intracranial stimulation therapy for epilepsy. Neurotherapeutics 6, 238-243. doi: 10.1016/j.nurt.2009.01.022
Slutzky, M. W., Jordan, L. R., Krieg, T., Chen, M., Mogul, D. J., and Miller, L. E. (2010). Optimal spacing of surface electrode arrays for brain-machine interface applications. J. Neural Eng. 7:26004. doi: 10.1088/1741-2560/7/2/026004

Stanic, U., Acimović-Janezic, R., Gros, N., Trnkoczy, A., Bajd, T., and Kljajić, M. (1978). Multichannel electrical stimulation for correction of hemiplegic gait. Methodology and preliminary results. Scand. J. Rehabil. Med. 10, 75-92.

Stein, R. B., Charles, D., Davis, L., Jhamandas, J., Mannard, A., and Nichols, T. R. (1975). Principles underlying new methods for chronic neural recording. Can. J. Neurol. Sci. 2, 235-244.

Strange, K. D., and Hoffer, J. A. (1999). Restoration of use of paralyzed limb muscles using sensory nerve signals for state control of FES-assisted walking. IEEE Trans. Rehabil. Eng. 7, 289-300. doi: 10.1109/86.788466

Suner, S., Fellows, M. R., Vargas-Irwin, C., Nakata, G. K., and Donoghue, J. P. (2005). Reliability of signals from a chronically implanted, silicon-based electrode array in non-human primate primary motor cortex. IEEE Trans. Neural Syst. Rehabil. Eng. 13, 524-541. doi: 10.1109/TNSRE.2005.857687

Sunshine, M. D., Cho, F. S., Lockwood, D. R., Fechko, A. S., Kasten, M. R., and Moritz, C. T. (2013). Cervical intraspinal microstimulation evokes robust forelimb movements before and after injury. J. Neural Eng. 10:036001. doi: $10.1088 / 1741-2560 / 10 / 3 / 036001$

Tai, C., Booth, A. M., Robinson, C. J., de Groat, W. C., and Roppolo, J. R. (2000). Multimicroelectrode stimulation within the cat L6 spinal cord: influences of electrode combinations and stimulus interleave time on knee joint extension torque. IEEE Trans. Rehabil. Eng. 8, 1-10. doi: 10.1109/86. 830943

Takmakov, P., Zachek, M. K., Keithley, R. B., Walsh, P. L., Donley, C., McCarty, G. S., et al. (2010). Carbon microelectrodes with a renewable surface. Anal. Chem. 82, 2020-2028. doi: 10.1021/ac902753x

Tan, W., Zou, Q., Kim, E. S., and Loeb, G. E. (2004). "Sensing human arm posture with implantable sensors," in IEEE (San Francisco, CA), 4290-4293.

Tanae, H., Holcomb, W. G., Yasuda, R., Hogan, J. F., and Glenn, W. W. (1973). Electrical nerve fatigue: advantages of an alternating bidirectional waveform. J. Surg. Res. 15, 14-21. doi: 10.1016/0022-4804(73)90158-3

Taylor, D. M., Tillery, S. I. H., and Schwartz, A. B. (2002). Direct cortical control of 3D neuroprosthetic devices. Science 296, 1829-1832. doi: 10.1126/science. 1070291

Teixeira, E., Jayaraman, G., Shue, G., Crago, P. E., Loparo, K., and Chizek, H. J. (1991). "Feedback control of nonlinear multiplicative system using neural networks: an application to electrically stimulated Muscle," in IEEE (Dayton, OH), 1-3.

Tresch, M. C., and Bizzi, E. (1999). Responses to spinal microstimulation in the chronically spinalized rat and their relationship to spinal systems activated by low threshold cutaneous stimulation. Exp. Brain Res. 129, 401-416. doi: 10.1007/s002210050908

Triolo, R. J., Bieri, C., Uhlir, J., Kobetic, R., Scheiner, A., and Marsolais, E. B. (1996). Implanted functional neuromuscular stimulation systems for individuals with cervical spinal cord injuries: clinical case reports. Arch. Phys. Med. Rehabil. 77, 1119-1128.

Triolo, R. J., Liu, M. Q., Kobetic, R., and Uhlir, J. P. (2001). Selectivity of intramuscular stimulating electrodes in the lower limbs. J. Rehabil. Res. Dev. 38, 533-544.

van den Brand, R., Heutschi, J., Barraud, Q., DiGiovanna, J., Bartholdi, K., Huerlimann, M., et al. (2012). Restoring voluntary control of locomotion after paralyzing spinal cord injury. Science 336, 1182-1185. doi: $10.1126 /$ science. 1217416

Wang, W., Collinger, J. L., Degenhart, A. D., Tyler-Kabara, E. C., Schwartz, A. B., Moran, D. W., et al. (2013). An electrocorticographic brain interface in an individual with Tetraplegia. PLOS ONE 8:e55344. doi: 10.1371/journal.pone.0055344

Wang, W., Degenhart, A. D., Collinger, J. L., Vinjamuri, R., Sudre, G. P., Adelson, P. D., et al. (2009). Human motor cortical activity recorded with Micro-ECoG electrodes, during individual finger movements. Conf. Proc. IEEE Eng. Med. Biol. Soc. 2009, 586-589. doi: 10.1109/IEMBS.2009. 5333704

Wang, W., Sudre, G. P., Xu, Y., Kass, R. E., Collinger, J. L., Degenhart, A. D., et al. (2010). Decoding and cortical source localization for intended movement direction with MEG. J. Neurophysiol. 104, 2451-2461. doi: 10.1152/jn.00239.2010

Watson, C., Paxinos, G., and Kayalioglu, G. (2009). The Spinal Cord. London: Academic Press. 
Wessberg, J., Stambaugh, C. R., Kralik, J. D., Beck, P. D., Laubach, M., Chapin, J. K., et al. (2000). Real-time prediction of hand trajectory by ensembles of cortical neurons in primates. Nature 408, 361-365. doi: 10.1038/35042582

Wilson, J. A., Felton, E. A., Garell, P. C., Schalk, G., and Williams, J. C. (2006). ECoG factors underlying multimodal control of a brain-computer interface. IEEE Trans. Neural Syst. Rehabil. Eng. 14, 246-250. doi: 10.1109/TNSRE.2006. 875570

Yakovenko, S., Kowalczewski, J., and Prochazka, A. (2007). Intraspinal stimulation caudal to spinal cord transections in rats. Testing the propriospinal hypothesis. J. Neurophysiol. 97, 2570-2574. doi: 10.1152/jn.00814.2006

Yanagisawa, T., Hirata, M., Saitoh, Y., Goto, T., Kishima, H., Fukuma, R., et al (2011). Real-time control of a prosthetic hand using human electrocorticography signals. J. Neurosurg. 114, 1715-1722. doi: 10.3171/2011.1.JNS101421

Yang, L., Wilke, C., Brinkmann, B., Worrell, G. A., and He, B. (2011). Dynamic imaging of ictal oscillations using non-invasive high-resolution EEG. Neuroimage 56, 1908-1917. doi: 10.1016/j.neuroimage.2011.03.043

Yoshida, N., Tomita, Y., Honda, S., and Saitoh, E. (2002). Functional neuromuscular stimulation for articular angle control with an inverse dynamics model tuned by a neural network. Ergonomics 45, 649-662. doi: 10.1080/00140130210 142074

Zhang, Q., Hayashibe, M., and Azevedo-Coste, C. (2013). Evoked electromyography-based closed-loop torque control in functional electrical stimulation. IEEE Trans. Biomed. Eng. 60, 2299-2307. doi: 10.1109/TBME.2013.2253777

Conflict of Interest Statement: Intellectual property licensed to Boston Scientific (J. Luis Lujan). The authors declare that the research was conducted in the absence of any commercial or financial relationships that could be construed as a potential conflict of interest.

Received: 06 April 2014; accepted: 31 August 2014; published online: 17 September 2014.

Citation: Grahn PJ, Mallory GW, Berry BM, Hachmann JT, Lobel DA and Lujan $J L$ (2014) Restoration of motor function following spinal cord injury via optimal control of intraspinal microstimulation: toward a next generation closed-loop neural prosthesis. Front. Neurosci. 8:296. doi: 10.3389/fnins.2014.00296

This article was submitted to Neuroprosthetics, a section of the journal Frontiers in Neuroscience.

Copyright (C) 2014 Grahn, Mallory, Berry, Hachmann, Lobel and Lujan. This is an open-access article distributed under the terms of the Creative Commons Attribution License (CC BY). The use, distribution or reproduction in other forums is permitted, provided the original author(s) or licensor are credited and that the original publication in this journal is cited, in accordance with accepted academic practice. No use, distribution or reproduction is permitted which does not comply with these terms. 